\title{
Crowdsourcing Designs: A Synthesis of Literatures
}

\author{
Helen K. Liu \\ The University of Hong Kong \\ hkliu9@hku.hk
}

\begin{abstract}
Crowdsourcing is a phenomenon emerging in various sectors and industries that provides an opportunity for governments to collaborate with the public to generate information, deliver public services, or facilitate policy innovation. This review paper synthesizes prior research and practices on crowdsourcing from a variety of disciplines and focuses on the purpose, crowd, motivation, process design and outcomes. A process map for governments to design crowdsourcing is generated and three key actions are highlighted, namely incentive design, communication, and information aggregation.
\end{abstract}

\section{Introduction}

Crowdsourcing is the act of a company or institution taking a function once performed by internal employees or contractors and outsourcing it to a group of people through an open call on the Internet (Howe 2006). In the public sector, since 2015, the Director of the Office of Science and Technology Policy had issued memorandums to the executive departments and agencies regarding the adoption of citizen science and crowdsourcing projects (OSTP 2015). As part of the recent Open Government movement, governments have begun to outsource projects to the public that have been traditionally done within the government, such as the Peer to Patent initiative by the US Patent and Trademark Office, which has the public taking part in the patent review process (Noveck 2009), or Challenge.org operating an open call for innovative policy solutions (Mergel and Desouza 2013). Meanwhile, public agencies and research institutions, such as NASA, have engaged the public to perform simple research tasks to improve scientific research. Recently, studies showed how government can use technology and the Web to enhance governance and the capacity of the public in order to gather information, solve public problems, facilities innovation and enhance policy making through citizen-sourcing (Nam 2012; Brabham 2015).
However, managing and implementing crowdsourcing in the public sector presents several difficulties, including attracting the right crowd, avoiding manipulation by special interest groups, controlling the quality of contributions, and information overload (Lampe et al. 2014). Dalal et al. (2011) also highlights three main challenges of implementing crowdsourcing, namely the difficulty of gathering information from large and diverse groups, facilitating meaningful communication and interaction among contributors, and aggregating information so that the thought process of the group can be revealed. These difficulties create barriers for the public managers to adopt crowdsourcing in their operation.

The goal of this paper is to synthesize prior research across a variety of disciplines on and practices of utilizing crowdsourcing. The common themes across a diverse body of literature identify useful practices and reveal appropriate questions for future crowdsourcing opportunities in government. If crowdsourcing efforts are to become more common, how can academics, practitioners, and public administrators better understand this trend? What are the required design components to make crowdsourcing efforts effective?

\section{What is crowdsourcing?}

The diversity of existing definitions illustrates the variety of possible starting points for studying the concept systematically. Crowdsourcing is first identified by Howe (2006), as "the act of a company or institution taking a function once performed by their own employees and outsourcing it to an undefined network of people in the form of an open call." Examining the existing literatures on crowdsourcing, Estelles-Arolas and GonzalezLadron-de-Guerva (2012) further proposed crowdsourcing as "a type of participative online activity in which an individual, an institution, a nonprofit organization, or company proposes to a group of individuals of varying knowledge, heterogeneity, 
and number, via a flexible open call, the voluntary undertaking of a task." For the purpose of this paper, it is useful to begin with the following definition based on both Howe (2006) and Estelles-Arolas and Gonzalez-Ladron-de-Guerva (2012): Crowdsourcing involves outsourcers creating incentives for the crowd to voluntarily contribute to and generate the desired outcomes of the outsourcers through an open call on the Internet.

This definition is consistent with Estelles-Arolas and Gonzalez-Ladron-de-Guerva (2012), who identified eight unique characteristics of crowdsourcing, namely, (1) the existence of a clearly defined crowd; (2) the existence of a task with a clear goal; (3) a clear recompense received by the crowd; (4) a clearly identified crowdsourcer; (5) a clearly defined compensation to be received by the crowdsourcer; (6) an online assigned process of a participative type; (7) the use of an open call of variable extent; and (8) the use of the Internet (p.197).

By the end of 2015, a search for "crowdsourcing," "crowd source," "crowdsourced," and "crowdsource" in the Web of Science database resulted in 1,123 articles. Given the focus of this paper, our team selected articles focusing on design, strategic and management of implementing crowdsourcing rather technical papers about crowdsourcing. Our team also conducted a Google Scholar search to ensure that the inclusion of high impact articles. In sum, 218 articles were selected for our review.

It is important to note that crowdsourcing share certain characteristics with other similar concepts like wisdom of the crowd, open innovation, and collective intelligence. But, due to the space, we cannot discuss all of them in our review. Also, we acknowledge that the review is not comprehensive, given a fast growing in the number of publications on crowdsourcing in conference proceedings and other working papers.

Most of the discussed crowdsourcing projects in the literature can be broadly classified into two types. First, innovation-driven crowdsourcing projects focus on tapping the crowd for innovative ideas. This type of crowdsourcing replaces the traditional research and development (R\&D) departments with the crowds' knowledge through an open call for ideas or solutions to a complex problem, such as in InnoCentive (Blohm, Leimeister, and Krcmar 2013; Lakhani et al. 2007), Dell's IdeaStorm (Bayus 2013), and Challenge.gov (Desouza 2012). Second, servicedriven crowdsourcing focuses on getting the crowds to complete complex or large tasks through an open call for the accomplishment of smaller tasks assigned to individuals within the crowd, such as Galaxy Zoo for galaxy image classification (Tokarchuk, Cuel, and
Zamarian 2012) and Peer to Patent for patent review (Noveck 2009). Service-driven crowdsourcing projects utilize crowds' abilities and knowledge to help the outsourcers improve or carry out services originally conducted by the outsourcers. Table 1 presents the selected prominent and well-studied cases from the research on crowdsourcing, categorized by service and innovation driven crowdsourcing projects.

Table 1 Selected crowdsourcing projects classified by service and innovation purpose

\begin{tabular}{|c|c|c|}
\hline Platform/Case & Purpose(s) & Selective References \\
\hline \multicolumn{3}{|c|}{ Service Driven Crowdsowrcing Project } \\
\hline $\begin{array}{l}\text { Amazon's } \\
\text { Mechanical Turk }\end{array}$ & $\begin{array}{l}\text { An internet marketplace that enables individuals, businesses and } \\
\text { organizations to find workforce to complete human intelligence } \\
\text { tasks (HITs), which are tasks that can be done better by humans } \\
\text { than computers. }\end{array}$ & $\begin{array}{l}\text { Kaufmann et al. (2011); } \\
\text { Tokarchuk et al. (2012); } \\
\text { Behrend et al. (2011); Chandler } \\
\text { and Kapelner (2013) }\end{array}$ \\
\hline $\begin{array}{l}\text { Galaxy Zoo } \\
\text { (Nonprofit) }\end{array}$ & $\begin{array}{l}\text { Astronomical projects hosted by Zooniverse and the Cornell Lab } \\
\text { of Ornithology aimed at mobilizing online volunteers to visually } \\
\text { classify billions of images of galaxies drawn from NASA's } \\
\text { Hubble Space Telescope archive. These classifications provide } \\
\text { scientists with valuable information on the formation of galaxies. }\end{array}$ & $\begin{array}{l}\text { Tokarchuk, Cuel and Zamarian } \\
\text { (2012); Franzoni and } \\
\text { Sauermann (2014) }\end{array}$ \\
\hline $\begin{array}{l}\text { Peer-to-Patent } \\
\text { (Government) }\end{array}$ & $\begin{array}{l}\text { A pilot project between the New York Law School and the U.S. } \\
\text { Patent and Trademark Office, ask the online volunteers to } \\
\text { undertake review and research of about } 1000 \text { patent applications. }\end{array}$ & $\begin{array}{l}\text { Noveck (2009); Brabham } \\
\text { (2010) }\end{array}$ \\
\hline $\begin{array}{l}\text { Goldcorp } \\
\text { (Private) }\end{array}$ & $\begin{array}{l}\text { A Canadian gold mining company, inviting people from all } \\
\text { around the word to examine the geologic } \\
\text { data and help identify potential sites where millions of ounces of } \\
\text { gold will be found. }\end{array}$ & $\begin{array}{l}\text { Marjanovic, Fry and Chataway } \\
\text { (2012); Blohm, Leimeister and } \\
\text { Krcmar (2013) }\end{array}$ \\
\hline \multicolumn{3}{|c|}{ Innovation Driven Crowdsourcing Project } \\
\hline $\begin{array}{l}\text { Dell's IdeaStorm } \\
\text { (Private) }\end{array}$ & $\begin{array}{l}\text { An online brainstorming community in which participants are } \\
\text { asked to keep on proposing big or small ideas that might } \\
\text { improve Dell's products and services }\end{array}$ & Bayus (2012) \\
\hline $\begin{array}{l}\text { Innocentive } \\
\text { (Private) }\end{array}$ & $\begin{array}{l}\text { An online platform in which to bridge a community of solution } \\
\text { seekers, usually companies who are unable to solve their } \\
\text { problems internally, who issue challenges to be answered by an } \\
\text { online community of solution providers who receive cash } \\
\text { awards. The platform thus provides research and development } \\
\text { solutions for a broad range of well-defined and scoped, scientific } \\
\text { and engineering challenges. }\end{array}$ & $\begin{array}{l}\text { Marjanovic, Fry and Chataway } \\
\text { (2012); Lakhani et al. (2007); } \\
\text { Blohm, Leimeister and Krcmar } \\
\text { (2013) }\end{array}$ \\
\hline $\begin{array}{l}\text { Next Stop Design } \\
\text { Project } \\
\text { (Government) }\end{array}$ & $\begin{array}{l}\text { A project between the Federal Transit Administration and the } \\
\text { Utah Transit Authority focused on the application of } \\
\text { crowdsourcing to bus stop design at the neighborhood scale by } \\
\text { allowing participants in Salt Lake City to submit and select } \\
\text { design for their ideal bus shop shelter. }\end{array}$ & $\begin{array}{l}\text { Brabham (2010); Brabham } \\
\text { (2012); Brabham (2014) }\end{array}$ \\
\hline $\begin{array}{l}\text { Threadless } \\
\text { (Private) }\end{array}$ & $\begin{array}{l}\text { A Chicago-based company that call for tee shirt design } \\
\text { submission online. Users can submit their own designs to } \\
\text { Threadless, where they are voted on for a 10-day period by other } \\
\text { users in the community. Winning designers will get their designs } \\
\text { print on the tee for sale. }\end{array}$ & $\begin{array}{l}\text { Brabham (2010); Tokarchuk, } \\
\text { Cuel and Zamarian (2012); Li } \\
\text { and Hongjuan (2011) }\end{array}$ \\
\hline
\end{tabular}

Furthermore, from our review, crowdsourcing and its outcomes vary in terms of who, why, how, and what, thus this paper adopts a simple framework, displayed in figure 1 , elaborating on these key components by focusing on crowds, motivation, process design, and outcomes. These categories are developed through reviewing extant frameworks and review articles on crowdsourcing in different fields (e.g., Albors, Ramos, and Hervas 2008; Malone, Laubacher, and Dellarocas 2010; Brabham, 2013; Hosseini et al. 2014). This framework provides a structure for exploring the existing research about crowdsourcing across disciplines but is not intended 
to convey relationships and direction among the categories. Each component of the framework highlights the important findings and debates from the existing literature so that instructive lessons can be generated.

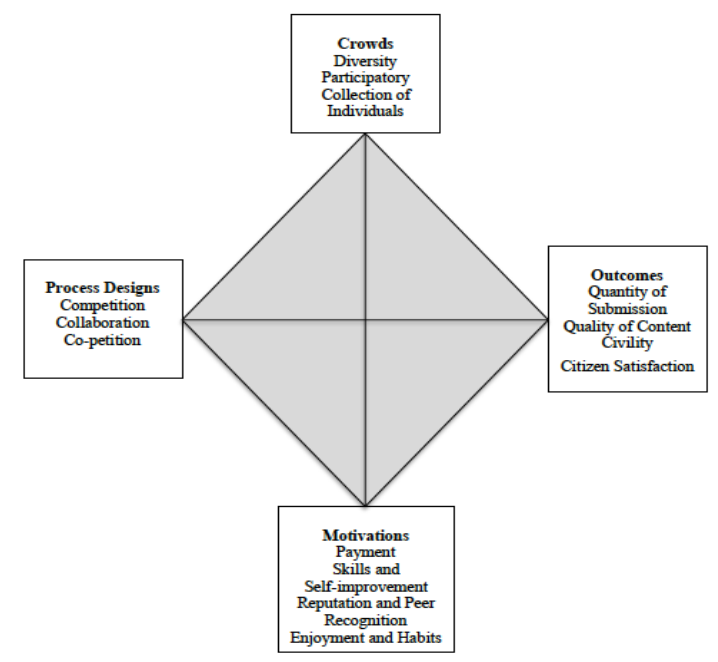

Figure 1 Conceptual framework for crowds ourcing lite rature review

\subsection{The crowds}

The crowds demonstrate diverse, participatory, and collective characteristics. First, diversity is one of the important criteria to form a wise crowd (Surowiecki 2004). Behrend et al. (2011) found that participants recruited from the crowdsourcing sites, such as Amazon Mechanical Turk, were more diverse in terms of education, employment status, and profession than the subjects from the university sample. Second, the crowds practice a participatory movement and are used to their involvement with the commercial culture (Kozinets et al. 2008). The crowds empower themselves to share, fund, produce, and even own the content or service generated (Heimans and Timms 2014). Third, the crowd is a collection of individuals with different backgrounds and abilities, and its performance depends on collective action. The outcomes of collective action might vary depending on the centrality and concentration of individuals' contributions.

Crowd is an aggregation of individuals with different backgrounds, purposes, capacities, knowledge, and different levels of commitment to contribute to the projects. For instance, Brabham (2012) points out that crowds can be professional and experts who opt in the crowdsourcing process, other than hobbyists or "amatueures." Kozinets et al. (2008) illustrate four types of online participants in terms of the concentration and level of knowledge. They define that "crowds are large organized groups who gather or are gathered together specifically to plan, manage, and completed the required tasks." He then made distinction between crowds and the other types of online participants: hives, mods, and swarms.

These characteristics highlight the uniqueness of crowdsourcing when compared to the management of a department. First, an open call is on the Internet, which creates uncertainty and challenges regarding participation. Second, voluntary contribution indicates that the relationship is informal and lacks legal constraint for enforcing the agreement between the outsourcers and crowd, thus presenting new challenges when designing incentive strategies. Third, because the crowd is a composition of individuals, generating ideas and works presents new challenges in information selection and aggregation. Finally, because the process of generating desired outcomes is transparent and open on the Internet, using outcomes as end results should be approached cautiously, and additional consideration should be given to understanding and measuring the means that produced the results.

\subsection{Motivation}

The existing literature shows diverse motivations for participation in crowdsourcing projects. Four frequently discussed motivations are as follows: Monetary incentive is important for crowds to participate in crowdsourcing projects because they treat those projects as either full- or part-time jobs for regular income (Tokarchuk, Cuel, and Zamarian 2012). Apart from financial incentives, some crowds are motivated to join crowdsourcing projects because they can learn new skills and achieve selfimprovement through their contribution to the projects (Crump et al. 2013; Kaufmann, Schulze, and Veit 2011; Kazai et al. 2013; Pilz and Gewald 2013). Others want to build reputation and gain peer recognition by interacting with other like-minded persons through crowdsourcing projects, as found in Galaxy Zoo (Tokarchuk, Cuel, and Zamarian 2012), and the Next Stop Design project (Brabham 2012). And still, some crowds contribute to projects as a hobby for their enjoyment, like Galaxy Zoo is for astronomy fan (Tokarchuk, Cuel, and Zamarian 2012), while Threadless was for the graphic designers (Brabham 2010). Table 2 shows the selective motivation and incentives discussed in the literature on motivating crowds to contribute.

Existing studies debate how different incentives might induce motivation to just participate or to contribute high quality content. Župič (2013) argues that monetary incentives might increasingly crowd 
out the intrinsic motivating factors of productive members. Garcia Martinez and Walton (2014) also find that monetary awards can increase the size of the participation but not directly the quality of the contribution. They argue that monetary awards can only indirectly influence the quality of the ideas because of the increase of the size of the crowd and the likelihood of generating a good idea. Therefore, other studies have shown that intrinsic motivations, such as empowerment, self-improvement, and reputation building can better sustain the contribution as well as improve the quality of contributions.

Table 2 Motivations for participating and contributing crowds ourcing projects

\begin{tabular}{l}
\hline \multicolumn{1}{c}{ Motivation } \\
\hline Payment \\
Brabham (2010); \\
Tokarchuk, Cuel and Zamarian (2012) \\
$\quad$ Threadless (prizes) \\
Newsom (2013) \\
Manor Labs
\end{tabular}

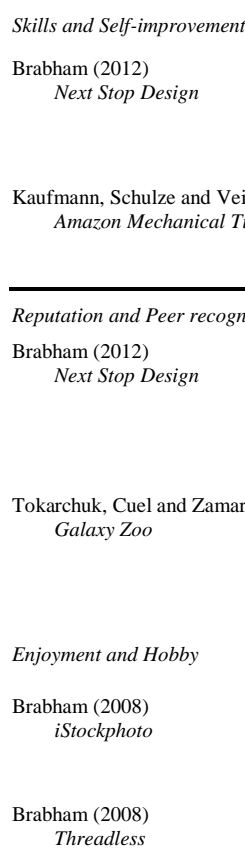
production the outsourcers and the crowds as well as among the crowds. There is also an emerging trend of adopting a co-opetition process. These process designs employ a variety of methods:

Competition: (1) Voting and commenting. These are the most commonly adopted methods for crowds to evaluate and improve the ideas and information they generate (Saxton, Oh, and Kishore 2013). For instance, Threadless ( $\mathrm{Li}$ and Hongjuan 2011) allows members to vote and comment on each post or idea (See appendix C figure 2.3). (2) Appropriate rating system. This is a refinement process of the votes and comments received from the crowds or experts in order to improve the quality and selection of information. An example can be seen in Yelp (Dellarocas 2010), which provides online reviews of restaurants and entertainment. A competitive The winning T-shirt design submissions to Threadessowelsodadcing process often involves participants with cash and gift certificates. The participants thus make
submissions to get a chance to make money, as we $\mathbb{Q}$ manpeting to win a prize for having the best idea or opportunity for freelance work or full time-design workution to an open call or challenge. For instance, Participants receive a made-up currency called Innobucks for their.
participation and submission of ideas in the platfortnnno entive partnered with Prize4Life to call for a innobucks each). Participants thus actively submit ideas inprofer to to measuring the progression of purchases and for discounts in local restaurants anAfhrnyotrophic Lateral Sclerosis (ALS) in patients. In 2006, the award of $\$ 1$ million was given to Dr. Next Stop Design allows private designers to subntienward Rutkove for his identification of a biomarker an online competition for bus stops. Incorporating tha thatictiatrsigrovide information cheaper and quicker for rethink about art, public space, and public transit. Falininiagalfetrials of ALS drugs (InnoCentive 2014). With that they acquire new tools and topical domains new interactive technology and communication tools, Some HITs are only available to users with certain qualifications.
Participation in these tasks is motivated by participanontestatsiohave been run through the Internet, where of their advancement in skills of importance for possiblempteripleely access and rank ideas and make further
advantages in the future comments.

Next Stop Design allows users to rate and comment the Coesigns. Those who got positive feedback enjoy the facts theamereatte and modify each other's content online their designs, as well as the recognition from other professionals.
Also, such peer recognition, as a core of the normathataugh that technology called wiki. In the case of creative professions, serves as a step towards fame Futuffrue Melbourne (Liu 2016), citizens can use the the designers to socialize and communicate with each other. It alfofraguresthth development plan. Collaborative process is research and scientific publications that are based on patticipants
contribution in the Galazy Zoo and recognize the vanothemasolternative design that aggregates pieces of

information from each individual in the crowd through a wiki, such as Wikipedia (Boudreau and The crowdsourcing site is new hybrid hobby/work tak iStockers derive fun and enjoyment from creating, Hipipgipe pnd2005). In Linux, 700 engineers work with commenting on photographs, videos and illustrations, in dddition to
the making of real money
hundreds of open-source communities to create a A vibrant online community exists with communitrangienaliof software products. Software quality is

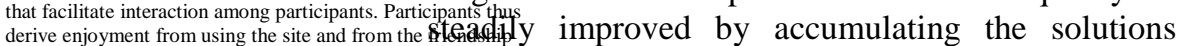
derive enjoyment from using the site and from the
developed, and obsession/ addiction proposed by each individual engineer (Boudreau and Lakhani 2013). Successful collaboration in an online community requires participants to reveal their knowledge in a transparent environment and share the outcomes of their effort jointly (Von Hippel and Krogh 2003).

Co-opetition: Community. Co-opetition is "a situation where competitors simultaneously cooperate and compete with each other" (Hutter et al. 2011, 5). Several studies argue that an effective design should namely competitive and collaborative, for information aggregation and communication between 
combine both competition and collaboration and build a community (Bullinger et al. 2010; Hutter et al. 2011; Lampel et al. 2012; Majchrzak and Malhotra 2013; Almirall, Lee, and Majchrzak 2014). Hutter et al.'s (2011) study finds that the winners of the projects are also the top commenters, and the best process design is one that enables a competitive participation with a cooperation climate that allows users to improve the quality of submitted ideas through constructive commenting. Such a community-based approach could optimize openness, allow negotiation of needed resources among participants (such as data information), and internalize the priority setting within the system (Almirall, Lee, and Majchrzak 2014).

\subsection{Outcomes}

The quality of outcomes generated by the crowd has received much attention in the existing research (Blohm et al. 2011; Boudreau 2012; Leimeister et al. 2009; Majchrzak and Malhotra 2013), yet the findings on the quality of the outputs when compared with those from experts show mixed results. For innovation driven crowdsourcing, the evaluation of outcomes show mixed results. Because idea evaluation takes time, however, crowd members often spend little time in developing their own ideas or give little attention to learning from the others' ideas (Majchrzak and Malhotra 2013). So, little evidence currently supports that crowdsourcing model can drive more innovative ideas. However, studies do show that allowing customer participate in crowdsourcing projects of the company increases customer satisfaction (Dellarocas 2010; Poetz and Schreier 2012; Nishikawa, Schreier, and Ogawa 2013).

On the other hand, for the information and service driven crowdsourcing project, evidences show that crowd contribution can be as good as the ones from the expert (Clery 2012; Anastasiou and Gupta 2011). When simple and clear instruction are provided to the crowds, See et al. (2013) found that the crowds can improve the quality of information faster than the experts. This indicates the importance of designing effective means to aggregate information from the crowds.

\section{A design map for crowdsourcing in the governments}

Figure 2 shows a design map for implementing crowdsourcing in the public sector. This design map includes the four key components of crowdsourcing and three key actions that crowdsourcing mangers should consider when implementing crowdsourcing. First, the government should incentivize the crowd to participate and contribute to the crowdsourcing project. Second, the government should communicate with the participants directly or facilitate communication among the participants. Third, the government needs to aggregate the outputs from the participant into outcomes.

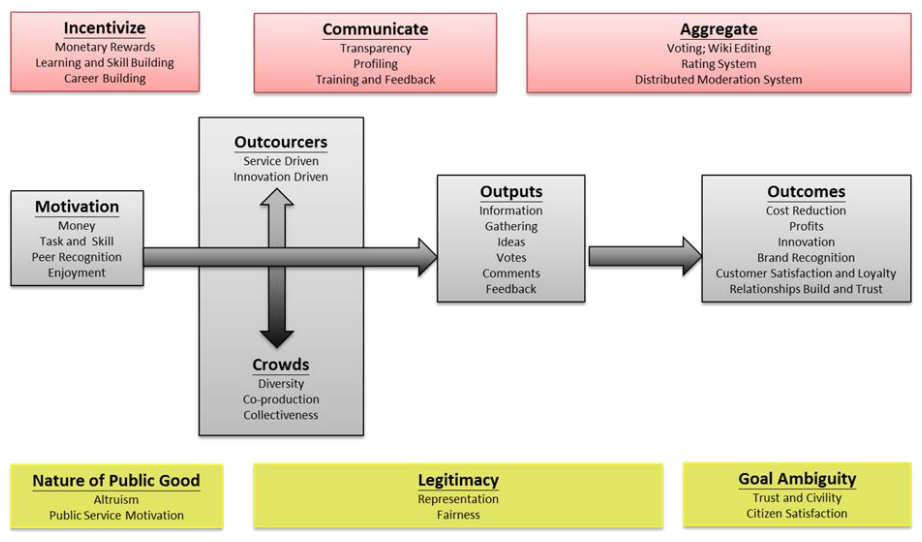

Figure 2 Crowdsourcing design Process

\subsection{Strategic design of incentives}

The focuses of recent studies have also shifted from "what" motivates people to "how" to motivate people. Studies on monetary incentives start to investigate how money might influence crowds' participation and performance and what amount can induce the desired outcomes (Garcia Martinez and Walton 2014). For instance, they found that money can only increase participation, but not the quality of the idea itself. Therefore, the larger the amount of the monetary incentives provided, the more ideas would be submitted and therefore the greater the likelihood of generating a good idea.

Another important study that discusses strategies on incentive design is by Tokarchuk et al. (2012). Through reviewing the existing motivational factors, they identify four variables that affect the motivation of the crowd and therefore the designers of the crowdsourcing projects should properly design strategies that provide incentives to motivate the crowds. They find that the intensity, direction, and persistence of worker performance are influenced by the goal, the nature of the tasks, the social structure, and the nature of the good. For instance, Tokarchuk et al. (2012) show that Galaxy Zoo and Moon Zoo platforms showed clear goals, low variety and specificity, neutral social structure, public good, and required only low-level skills. The participants were motivated simply by their interests in astronomy and 
aided by the capacity of the task dimensions. While platforms like Threadless show clear goals, require specific skills, hierarchical structure with democratic features (i.e., voting), and private good, they find that participants are also motivated by money and skills development.

Similarly, while understanding the importance of peer influence plays a key role of motivating the crowd to contribute, allowing the crowd to constructively post comments and exchange ideas becomes an important design to motivate the crowds. Bayus (2013) shows that posting comments to others who have different ideas is positively associated with the ideas that are selected and implemented in Dell's IdeaStorm. Therefore, it is important for the designer of the crowdsourcing project to incentivize social exchange activities. One way to do so is by making active contributors more visible, providing interaction opportunities in the community, and fostering responses from members in the case of IdeasProject for Nokia's (Kosonen et al. 2013).

\subsection{Communication}

Earlier case studies treat crowdsourcing as a bottom-up and decentralized process, and focus on how social media can help to enhance the horizontal communication among the members of the crowd (e.g., Bonabeau 2009). Recent studies focus on the implications of crowdsourcing to the firms to enhance their customer relationship because these social media serve as two-way and interactive tools that can foster greater customer engagement and brand recognition (Baron and Warnaby 2011; Djelassi et al. 2013).

For instance, in the Lay's contest of "create your flavor of potato chips," the company involved the finalist on its package cover and shared $1 \%$ of the product sales with the finalist for a year (Djelassi et al. 2013). A participant of the contest became a salesman of the company who is committed to promoting the company's value through crowdsourcing (Djelassi et al. 2013).

When consumers have become "prosumers" (Kozinets et al. 2008) and taken part in the production process, the company needs to treat the designing of a crowdsourcing initiative as a managerial question, not a technical one (Saxton, Oh, and Kishore 2013). Adaptation of a managerial control system in crowdsourcing becomes an important step to ensure the flow of communication between the outsourcers and the crowds, and the decision on which technical function (such as online voting or commenting) to be included in the process should be a managerial, rather than based on the IT package deal of a website company (Saxton et al. 2013).

\subsection{Information aggregation}

Moving from focuses of how the crowds produce tasks, more recent studies start to pay attention on how to efficiently and effectively aggregate the information and ideas generated from the crowds. From previously discussed public crowdsourcing cases, the public managers play a heavy role of reviewing, evaluating, and selecting of the work done by the crowds. For instance, the Open Government Dialogue consisted of three discussion phases. After the first public consultation on the Open Government policy phase is over, a small Advisory Board was formed to select a week-long discussion and ideas submitted in the platform in order to form potential topics for the Phase II discussion (Trudeau, 2009). Similarly, in the Peer to Patent case, patent review officers were placed at the final stage to review the report and research contributed from the crowds and make the final decision. While crowds in the idea generation competitions can vote for the best ideas, such as Challenge.gov, the crowds did not have input into how the winning ideas are implemented. The capability of crowds can be empowered further to address evaluation, selection, and monitoring.

Incorporating the crowds in the information aggregation process can help the selection and evaluation system to be more effective and efficient as well as enhance the user experiences. Studies have shown that when utilizing the crowd to provide assessment to the crowdsourcing process, the crowd can produce better results than experts in less time and with less cost (Carvalho, Lease, and Yilmaz 2010). Also, allowing the crowd to participate in the process of information selection enhance the experiences of the crowds. For instance, in the case of the Make History Project, run by the 9/11 Memorial Museum, Ellis (2014) argues that contributors don't just contribute narratives and artifacts, but also experience different perspectives when asked to combine stories together, and therefore they experience the sharing of the many stories. However, it also requires the outsourcers to be able to make a distinction between the different individual users within a crowd. The challenge is how to tell different individual's abilities in assessing information and to prevent and resolve disputes (Doan, Ramakrishnan, and Halevy 2011).

\section{Conclusions}


Crowdsourcing enables governments to empower the citizens to participate in the production of public services and the generation of policy innovations. Crowdsourcing has great potential to help governments reduce costs, bring in innovation, and build trust with their citizens, as this review has found in the private sector. This review accumulates knowledge on crowdsourcing for the public sector by presenting the key design components of crowdsourcing and discussing the evidences of effective designs of crowdsourcing across different disciplines. Given the success of crowdsourcing projects and their potential for the public sector, this emerging field will continue to grow. Table 3 summarizes potential actions under the three key design areas.

However, future studies should further address the transferability of private-sector crowdsourcing experiences and practices to the public sector in the following areas: (1) the nature of the public good. Several studies have addressed how the nature of the good might affect the motivation and incentive design (Tokarchuk et al. 2012) and productivity (Huberman et al. 2009) of the crowdsourcing. In Addition, more studies are needed to explore whether theories like public service motivation can better explain the motivation of the crowds in crowdsourcing in the public sector. (2) Also, legitimacy must be addressed; the method of how content and information are generated in the process and the representation of the final outcomes produced by the crowds are essential as well. (3) Finally, goal ambiguity is a unique characteristic in the public sector. Therefore, the ultimate impact of crowdsourcing should be to help governments achieve the attention they deserve from policy makers and scholars.

Table 3 Suggested Actions

\begin{tabular}{|c|c|}
\hline Key Action Areas & Issues to Avoid \\
\hline \multicolumn{2}{|l|}{ Incentive Design } \\
\hline$\diamond \quad \begin{array}{l}\text { Provide monetary rewards to } \\
\text { attract sufficient participants }\end{array}$ & $\begin{array}{l}\text { Avoid crowding- } \\
\text { out effect }\end{array}$ \\
\hline $\begin{array}{l}\diamond \text { Design tasks to build skills or } \\
\text { hobbies of the participants }\end{array}$ & $\begin{array}{l}\text { Prevent unfairness } \\
\text { perception }\end{array}$ \\
\hline 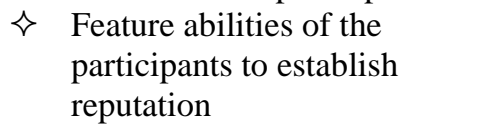 & Unclear objectives \\
\hline \multicolumn{2}{|l|}{ Communication Design } \\
\hline $\begin{array}{l}\diamond \quad \text { Make the decision rules } \\
\text { transparent }\end{array}$ & $\begin{array}{l}\text { Only for one-way } \\
\text { communication }\end{array}$ \\
\hline $\begin{array}{l}\diamond \text { Allow participates to set up } \\
\text { profiles and activity logs }\end{array}$ & $\begin{array}{l}\text { No or lack of staff } \\
\text { to manage the }\end{array}$ \\
\hline$\diamond \quad$ Provide timely feedbacks & process \\
\hline
\end{tabular}

\begin{tabular}{|c|c|c|c|}
\hline$\diamond$ & $\begin{array}{l}\text { Invite peer reviews through } \\
\text { voting and wiki editing }\end{array}$ & $\diamond$ & $\begin{array}{l}\text { Avoid self-voting } \\
\text { or commenting }\end{array}$ \\
\hline$\diamond$ & Establish a rating system & $\diamond$ & Prevent cheating \\
\hline$\diamond$ & $\begin{array}{l}\text { Adopt a distributed } \\
\text { moderation system }\end{array}$ & & $\begin{array}{l}\text { or inflating the } \\
\text { ranking }\end{array}$ \\
\hline
\end{tabular}

\section{References}

[1] Albors, Jordi, Juan C Ramos, and Jose L Hervas. 2008. "New Learning Network Paradigms: Communities of Objectives, Crowdsourcing, Wikis and Open Source." International Journal of Information Management no. 28 (3):194-202.

[2] Almirall, Esteve, Melissa Lee, and Ann Majchrzak. 2014. "Open Innovation Requires Integrated Competition-community ecosystems: Lessons Learned from Civic Open Innovation." Business Horizons no. 57 (3):391-400.

[3] Anastasiou, Dimitra, and Rajat Gupta. 2011. "Comparison of Crowdsourcing Translation with Machine Translation." Journal of Information Science no. 37 (6):637-659.

[4] Baron, S., \& Warnaby, G. 2011. "Individual customers' use and integration of resources: Empirical findings and organizational implications in the context of value co-creation." Industrial Marketing Management, 40(2): 211-218. doi:10.1016/j.indmarman.2010.06.033

[5] Bayus, Barry L. 2013. "Crowdsourcing New Product Ideas Over Time: An Analysis of the Dell IdeaStorm Community." Management Science no. 59 (1):226-244.

[6] Behrend, Tara S, David J Sharek, Adam W Meade, and Eric N Wiebe. 2011. "The Viability of Crowdsourcing for Survey Research." Behavior Research Methods no. 43 (3):800-813.

[7] Blohm, I., Bretschneider, U., Leimeister, J. M., and Krcmar, H. 2011. "Does collaboration among participants lead to better ideas in IT-based idea competitions? An empirical investigation." International Journal of Networking and Virtual Organisations, 9(2)(2): 106- 122.

[8] Blohm, Ivo, Jan Marco Leimeister, and Helmut Krcmar. 2013. "Crowdsourcing: How to Benefit from (Too) Many Great Ideas.” MIS Quarterly Executive. 
[9] Bonabeau, Eric. 2009. "Decisions 2.0: The Power of Collective Intelligence." MIT Sloan Management Review no. 50 (2):45-52.

[10] Boudreau, Kevin J. 2012. Let a thousand flowers bloom? An early look at large numbers of software app developers and patterns of innovation. Organization Science, 23(5): 1409-1427.

[11] Boudreau, Kevin J, and Karim R Lakhani. 2013. "Using the crowd as an innovation partner." Harvard Business Review no. 91 (4):60-69.

[12] Brabham, Daren C. 2010. "Moving the Crowd at Threadless: Motivations for Participation in a Crowdsourcing Application." Information, Communication \& Society no. 13 (8):1122-1145.

[13] Brabham, Daren C. 2012. "Motivations for Participation in a Crowdsourcing Application to Improve Public Engagement in Transit Planning." Journal of Applied Communication Research no. 40 (3):307-328.

[14] Brabham, D.C. (2012). "The Myth of Amateur Crowds." Information, Communication \& Society. pp.394-410.

[15] Brabham, D. C. (2013). "Using Crowdsourcing in Government" IBM Center for The Business of Government. Retrieved from http://www. businessofgovernment.

org/report/usingcrowdsourcing-government.

[16] Brabham, D.C., 2015. Crowdsourcing in the public sector. Washington, DC: Georgetown University Press.

[17] Bullinger, Angelika C, Anne-Katrin Neyer, Matthias Rass, and Kathrin M Moeslein. 2010. "Community-Based Innovation Contests: Where Competition Meets Cooperation." Creativity and Innovation Management 19 (3):290-303.

[18] Carvalho, V. R., Lease M. and Yilmaz, E. 2011. "Crowdsourcing for search evaluation." SIGIR Forum 44(2): 17-22.

[19] Chandler, Dana, and Adam Kapelner. 2013. "Breaking Monotony with Meaning: Motivation in Crowdsourcing Markets." Journal of Economic Behavior \& Organization no. 90:123-133.
[20] Clery, Daniel. 2011. "Galaxy zoo volunteers share pain and glory of research." Science 333 (6039):173-175.

[21] Crump, Matthew JC, John V McDonnell, and Todd M Gureckis. 2013. "Evaluating Amazon's Mechanical Turk as a Tool for Experimental Behavioral Research." PloS one no. 8 (3): e57410.

[22] Dalal, Siddhartha, Dmitry Khodyakov, Ramesh Srinivasan, Susan Straus, and John Adams. 2011. "ExpertLens: A System for Eliciting Opinions from a Large Pool of Non-collocated Experts with Diverse Knowledge." Technological Forecasting and Social Change no. 78 (8):1426-1444.

[23] Dellarocas, Chrysanthos. 2010. "Managing the Social Web-online Reputation Systems: How to Design One That Does What You Need." MIT Sloan Management Review no. 51 (3):33.

[24] Desouza Kevin C. 2012. "Challenge.gov: Using Competitions and Awards to Spur Innovation." IBM Center for the Business of Government: Using Technology Series. Retrieved from: http://www.cbs.dk/files/cbs.dk/challenge.gov_desouz a.pdf

[25] Djelassi, Souad, and Isabelle Decoopman. 2013. "Customers' Participation in Product Development through Crowdsourcing: Issues and Implications." Industrial Marketing Management no. 42 (5):683692.

[26] Doan, Anhai, Ramakrishnan Raghu, and Halevy Alon Y. 2011. "Crowdsourcing Systems on the World-Wide Web." Communications of the ACM 54 (4): $86-96$

[27] Ellis, Sally. 2014. "A History of Collaboration, a Future in Crowdsourcing: Positive Impacts of Cooperation on British Librarianship." Libri 64 (1):110. doi:10.1515/libri-2014-0001.

[28] Estellés-Arolas, Enrique, and Fernando González-Ladrón-de-Guevara. 2012. "Towards an Integrated Crowdsourcing Definition." Journal of Information Science no. 38 (2):189-200.

[29] Garcia Martinez, Marian, and Bryn Walton. 2014. "The Wisdom of Crowds: The Potential of Online Communities as a Tool for Data Analysis." Technovation no. 34 (4):203-214. 
[30] Heimans, Jeremy, and Henry Timms. 2014. "Understanding New Power." Harvard Business Review 92(12): 48-56.

[31] Hosseini, Mahmood, Keith Phalp, Jacqui Taylor, and Raian Ali. 2014. "The Four Pillars of Crowdsourcing: a Reference Model." In Research Challenges in Information Science (RCIS). Marrakech: IEEE.

[32] Howe, Jeff. 2006. "The Rise of Crowdsourcing." Wired Magazine no. 14 (6):1-4.

[33] Huberman, B. A., D. M. Romero, and F. Wu. 2009. "Crowdsourcing, Attention and Productivity." Journal of Information Science 35 (6):758-765. doi: 10.1177/0165551509346786.

[34] Hutter, Katja, Julia Hautz, Johann Füller, Julia Mueller, and Kurt Matzler. 2011. "Communitition: The Tension between Competition and Collaboration in Community-Based Design Contests." Creativity and Innovation Management no. 20 (1):3-21.

[35] Innocentive website. "Solutions of Note" http://www.innocentive.com/about-

innocentive/innovation-solutions-of-note. Accessed on August 30, 2014.

[36] Kaufmann, Nicolas, Thimo Schulze, and Daniel Veit. 2011. "More than Fun and Money. Worker Motivation in Crowdsourcing-a Study on Mechanical Turk."

[37] Kazai, Gabriella, Jaap Kamps, and Natasa MilicFrayling. 2013. "An Analysis of Human Factors and Label Accuracy in Crowdsourcing Relevance Judgments." Information Retrieval no. 16 (2):138178.

[38] Kosonen, M., Gan, C., Olander, H. \& Blomqvist, K. 2013. "My Idea Is Our Idea: Supporting User-

Driven Innovation Activities in Crowdsourcing Communities." International Journal of

Innovation Management. 17 (03): 1340-010. Retrieved from:

http://dx.doi.org/10.1142/S1363919613400100

[39] Kozinets, Robert V, Andrea Hemetsberger, and Hope Jensen Schau. 2008. "The wisdom of consumer crowds collective innovation in the age of networked marketing." Journal of Macromarketing 28 (4):339354.
[40] Lakhani, K.R., Jeppesen, L.B., Lohse, P.A. \& Panetta, J.A. 2007. "The Value of Openness in Scientific Problem Solving." HBS Working Paper Number: 07-050. Cambridge: Harvard University. Retrieved July 10, 2007 from http://hbswk.hbs.edu/item/5612.html

[41] Lampe, Cliff, Paul Zube, Jusil Lee, Chul Hyun Park, and Erik Johnston. 2014. "Crowdsourcing Civility: A Natural Experiment Examining the Effects of Distributed Moderation in Online Forums." Government Information Quarterly no. 31 (2):317326.

[42] Lampel, Joseph, Pushkar P. Jha, and Ajay Bhalla. 2012. "Test-Driving the Future: How Design Competitions Are Changing Innovation." Academy of Management Perspectives 26 (2):71-85. doi: 10.5465/amp.2010.0068.

[43] Leimeister, Jan Marco, Michael Huber, Ulrich Bretschneider, and Helmut Krcmar. 2009. "Leveraging Crowdsourcing: Activation-supporting Components for IT-based Ideas Competition." Journal of Management Information Systems no. 26 (1):197-224.

[44] Lerner, Josh, and Jean Tirole. 2002. "Some Simple Economics of Open Source." The Journal of Industrial Economics no. 50 (2):197-234.

[45] Li, Z., and Hongjuan, Z. 2011. "Research of crowdsourcing model based on case study." Paper presented at the Service Systems and Service Management (ICSSSM), 2011 8th International Conference.

[46] Liu, Helen K. 2012. "Open Source, Crowdsourcing, and Public Engagement." Public Service, Governance and Web 2.0 Technologies, Future Trends in Social Media:181-199.

[47] Liu, Helen K. 2016. "Exploring Online Engagement in Public Policy Consultation: The Crowd or the Few?" Australian Journal of Public Administration. (online first).

[48] Liu, Q. (Ben), Karahanna, E., and Watson, R. T. 2011. "Unveiling user-generated content: Designing websites to best present customer reviews." Business Horizons 54(3): 231-240.

[49] Majchrzak, Ann, and Arvind Malhotra. 2013. "Towards an Information Systems Perspective and Research Agenda on Crowdsourcing for Innovation." 
The Journal of Strategic Information Systems no. 22 (4):257-268.

[50] Malone, Thomas W, Robert Laubacher, and Chrysanthos Dellarocas. 2010. "The Collective Intelligence Genome." IEEE Engineering Management Review no. 38 (3):38.

[51] Marjanovic, Sonja, Caroline Fry, and Joanna Chataway. 2012. "Crowdsourcing Based Business Models: In Search of Evidence for Innovation 2.0." Science and Public Policy: scs009.

[51] Mazzola, Daniele, and Alessandra Distefano. 2010. Crowdsourcing and the Participation Process for Problem Solving: the Case of BP. Paper read at Proceedings of ItAIS 2010 VII Conference of the Italian Chapter of AIS.

[52] Mergel, Ines, and Kevin C Desouza. 2013. "Implementing Open Innovation in the Public Sector: The Case of Challenge. gov." Public Administration Review no. 73 (6):882-890.

[53] Mergel, I. (2013). Social media adoption and resulting tactics in the US federal government. Government Information Quarterly, 30(2), 123-130.

[54] Nam, Taewoo. 2012. "Suggesting Frameworks of Citizen-sourcing via Government 2.0." Government Information Quarterly no. 29 (1):12-20.

[55] Trudeau, Lena. 2009. "Summary Analysis of the Open Government Brainstorm". The National Academy of Public Administration. Retrieved from: http://ncdd.org/exchange/files/docs/NAPA_analysis_ opengovtbrainstorm.pdf

[56] Newsom, Gavin. 2013. Citizenville: How to Take the Town Square Digital and Reinvent Government: Penguin.

[57] Nishikawa, Hidehiko, Martin Schreier, and Susumu Ogawa. 2013. "User-generated versus Designer-generated Products: A Performance Assessment at Muji." International Journal of Research in Marketing no. 30 (2):160-167.

[58] Noveck, Beth Simone Simone. 2009. Wiki Government: How Technology can Make Government Better, Democracy Stronger, and Citizens more Powerful: Brookings Institution Press.

[59] OSTP. 2015. "FACT SHEET: Empowering Students and Others through Citizen Science and
Crowdsourcing." Retrieved from: https://www.whitehouse.gov/sites/default/files/micro sites/ostp/citizen_science_backgrounder_03-2315.pdf

[60] Pilz, Dennis, and Gewald Heiko. 2013. "Does Money Matter? Motivational Factors for Participation in Paid- and Non-Profit-Crowdsourcing Communities." WIRTSCHAFTSINFORMATIK PROCEEDINGS 2013, Paper 37. Retrieved from: http://aisel.aisnet.org/wi2013/37

[61] Poetz, Marion K, and Martin Schreier. 2012. "The Value of Crowdsourcing: Can Users Really Compete with Professionals in Generating New Product Ideas?" Journal of Product Innovation Management no. 29 (2):245-256.

[62] Saxton, Gregory D, Onook Oh, and Rajiv Kishore. 2013. "Rules of Crowdsourcing: Models, Issues, and Systems of Control." Information Systems Management no. 30 (1):2-20.

[63] Schenk, Eric, and Guittard Claude. 2010. "Towards a characterization of crowdsourcing practices." Journal of Innovation Economics, 7(1): 120 .

[64] See, Linda, Alexis Comber, Carl Salk, Steffen Fritz, Marijn van der Velde, Christoph Perger, Christian Schill, Ian McCallum, Florian Kraxner, and Michael Obersteiner. 2013. "Comparing the Quality of Crowdsourced Data Contributed by Expert and Non-experts." PloS One no. 8 (7): e69958.

[65] Surowiecki, James. 2004. The wisdom of crowds: Random House LLC.

[66] Tokarchuk, Oksana, Roberta Cuel, and Marco Zamarian. 2012. "Analyzing Crowd Labor and Designing Incentives for Humans in the Loop." Internet Computing, IEEE no. 16 (5):45-51.

[67] Von Hippel, Eric von. 2005. Democratizing Innovation. MIT press.

[68] Von Hippel Eric, and Georg von Krogh. 2003. "Open Source Software and the "Private-collective" Innovation model: Issues for Organization Science." Organization science no. 14 (2):209-223.

[69] Župič, Ivan. 2013. "Social Media as Enabler of Crowdsourcing." In Social Media in Human Resources Management, 243-255. Emerald Group Publishing Limited. 